\title{
O Processo de Liderança e a Gestão do Conhecimento Organizacional: as prátICAS das maIORES INDÚSTRIAS CATARINENSES
}

\author{
The Process of Leadership and the Organizational Knowledge \\ Management: the practicy of the largest industries of Santa Catarina
}

\section{Dante Girardi}

Professor do Departamento de Ciências da Administração, Universidade Federal de Santa Catarina - Florianópolis - SC, Brasil.

E-mail: dante.girardi@terra.com.br

Irineu Manoel de Souza

Professor do Departamento de Ciências da Administração, Universidade Federal de Santa Catarina - Florianópolis - SC, Brasil.

E-mail: irineu@cse.ufsc.br

Júlia de Freitas Girardi

Graduanda do Curso de Psicologia, Universidade Federal de Santa Catarina - Florianópolis - SC, Brasil.

E-mail: julia.girardii@hotmail.com

\section{Resumo}

O objetivo deste artigo é apresentar as práticas de liderança das indústrias catarinenses de grande porte e a sua contribuição para a Gestão do Conhecimento. A competitividade organizacional está relacionada às pessoas e à capacidade das empresas de fomentar o desenvolvimento constante do conhecimento. Por meio da liderança, os gestores e a Gestão de Pessoas criam comprometimento e melhoram os resultados das organizações. A metodologia adotada seguiu a linha da pesquisa qualitativa, descritiva e aplicada. Foram entrevistadas as sete maiores indústrias do Estado de Santa Catarina, em número de colaboradores. Utilizou-se também a pesquisa documental. Os dados foram analisados pela técnica de análise de conteúdo. Observou-se que a liderança está presente na maioria das empresas estudadas, por meio de programas formais de desenvolvimento de líderes ou de ações relacionadas à liderança. Conclui-se que as empresas têm o foco nas pessoas e no conhecimento, em maior ou menor grau, estando algumas em fase de transição e de revisão dos programas voltados ao desenvolvimento dos seus talentos e à Gestão do Conhecimento.

Palavras-chave: Gestão de Pessoas. Liderança. Conhecimento. Gestão do Conhecimento.

\section{Abstract}

The aim of this article is to introduce the practices of leadership in the largest industries of Santa Catarina and their contribution to the Knowledge Management. The organization competitiveness is related to the people and to the capacity of the companies to improve the constant development of knowledge. Using the leadership, the managers and the People Management have created compromise and improved the results of the organizations. The adopted methodology followed the qualitative methodology, descriptive and applied research. There were interviewed the seven largest industries of the state of Santa Catarina, in number of collaborators. The data were analyzed by the technique of analysis of content. It has been observed that the leadership is present in the most of the studied companies, by the use of formal programs of development of leaders or of actions related to leadership. It is concluded that the companies have the focus in the people and in the knowledge, in bigger or smaller degree, but some of them are in phase of transition and revision of programs towards the development of their talents and of the Knowledge Management.

Key words: People Management. Leadership. Knowledge. Knowledge Management. 


\section{INTRODUÇÃO}

A competitividade organizacional depende de diversos elementos, sendo o resultado da combinação eficiente dos recursos, processos, tecnologias, estratégias e estrutura, e da adoção de políticas e práticas de gestão que sustentem o desenvolvimento contínuo da organização.

Nesse contexto, o conhecimento se configura como ativo de valor, gerador de diferencial competitivo. As organizações contemporâneas, buscando a competitividade, investem nos talentos humanos $e$ no desenvolvimento do conhecimento, por meio de modelos de gestão que favoreçam o aprendizado, a criatividade, o envolvimento e a inovação.

O conhecimento ganhou ênfase nos anos de 1990, como principal elemento de competitividade organizacional. Conhecimento é uma "crença verdadeira justificada"(NONAKA; TAKEUCHI, 1997, p. 99) com capacidade de gerar novos conhecimentos e disseminá-los na empresa, incorporando-os aos produtos, serviços e sistemas. As organizações precisam desenvolver a capacidade de aprender (GEUS, 1999), estimulando o desenvolvimento das pessoas e aproveitando todo o potencial dos talentos humanos. As pessoas formam o capital intelectual das organizações, agregando valores na medida em que são estimuladas e reconhecidas no seu ambiente de trabalho. (PACHECO, 2005)

Antes, as empresas queriam dos profissionais ações operacionais, sem comprometimento com os seus objetivos e estratégias. Atualmente, com a percepção do valor das pessoas para o sucesso de qualquer organização e da ação dos gestores para a mudança, estes assumem participação estratégica, em conjunto com o gestor de pessoas, influenciando na qualidade das decisões. Assim, cabe aos gestores integrar os objetivos organizacionais e os objetivos pessoais, tornar efetivos os processos de Gestão de Pessoas e desenvolver competências estratégicas (PACHECO, 2005), favorecendo a aprendizagem e o conhecimento.

A liderança é um desafio às organizações, fazendo parte do processo de Aplicação de Pessoas. Sua prática pelos gestores contribui significativamente para a construção do conhecimento organizacional. Cavalcanti (2009) reflete que as organizações devem conseguir resultados por meio das pessoas, o que enfatiza a liderança, amplia a percepção do papel dos líderes, os quais passam a considerar também os aspectos intangíveis da sua gestão, como forma de apoiar novos valores, atitudes e padrões de comportamento. Dessa forma, a liderança tem papel essencial na Gestão do Conhecimento nas organizações.

Os investimentos das indústrias catarinenses, até 2010, demonstram a busca contínua por conhecimento e inovação. Dados da Federação das Indústrias do Estado de Santa Catarina - FIESC (2008) indicam aquisição de equipamentos, atualização tecnológica, aumento da capacidade produtiva e desenvolvimento de produtos. Em 2007, as atividades industriais de melhor desempenho no Estado foram na área de fabricação de máquinas, aparelhos e materiais elétricos, com $14,34 \%$ de incremento da produção em relação a 2006. A produção não havia crescido tanto desde 2000 , que marcou crescimento de $18,85 \%$ na produção industrial de máquinas e equipamentos. Quanto ao capital humano, o Ministério do Trabalho e Emprego registrou em 2007 expansão do emprego formal, sendo 83,6 mil novos postos de trabalho em Santa Catarina, um aumento de 6,11\%. (FEDERAÇÃO... 2008)

Portanto, a presente pesquisa objetiva apresentar as práticas de liderança nas indústrias catarinenses de grande porte. Para isso, este artigo está organizado da seguinte forma: considerações iniciais relevantes sobre o tema e aspectos envolvidos, contextualização da Gestão de Pessoas e seus processos, caracterização do processo de Aplicação de Pessoas e da liderança como subprocesso e prática agregadora à Gestão do Conhecimento, procedimentos metodológicos utilizados, descrição das práticas de liderança nas maiores indústrias catarinenses e, finalmente, as conclusões do estudo.

\section{Uma Contextualização da Gestão de Pessoas e dos seus Processos}

O RH se transformou ao longo do tempo, buscando se adaptar às demandas do ambiente, das organizações e das pessoas. Para compreender melhor o papel da liderança na Gestão do Conhecimento nas organizações, é importante contextualizar a Gestão de Pessoas e os seus processos.

Nas organizações modernas, o RH configura-se como Gestão de Pessoas. Assume postura sistêmica 
e estratégica, atuando como consultoria interna, por meio dos seus processos alinhados à estratégia organizacional e integrados entre si, buscando elevar o desempenho, desenvolver o conhecimento e promover a inovação e a competitividade.

A Teoria Sistêmica de Bertalanffy, nos anos de 1930, trouxe a visão de inter-relação dos processos organizacionais. Contribuiu para o desenvolvimento do $\mathrm{RH}$, orientando as organizações para a busca do conhecimento global e, do alcance de melhores resultados, por meio dos indivíduos na sua totalidade e dos seus processos entendidos sob a perspectiva sistêmica.

A consultoria interna surgiu em empresas americanas e europeias nos anos de 1950, consolidando-se nos anos de 1990, sendo um resultado da demanda por mudanças na cultura, estrutura e práticas para a competitividade organizacional (JOHRI; COOPER; PROKOPENKO, 1998). Focado nas pessoas e no desenvolvimento, o $\mathrm{RH}$ passou a atuar sob a forma de consultoria interna, buscando efetividade nos seus processos. A Consultoria Interna de $\mathrm{RH}$ realiza atividades de apoio, orientação e supervisão para as demandas da organização (FRANÇA 2007). É uma atividade de cunho intelectual importante nas organizações, sendo os profissionais de $\mathrm{RH}$ os consultores internos (MANCIA, 1997), que buscam orientar e apoiar continuamente os gestores de linha na busca por profissionais qualificados, motivados e produtivos, em uma relação de parceria (CÂMARA; GUERRA; RODRIGUES, 1997), desenvolver a Gestão de Pessoas e a organização, gerenciando as pessoas de modo efetivo, valorizando as competências e o capital intelectual e agregando novas visões ao negócio. (LEITE et al., 2005)

A Gestão de Pessoas consolida-se nos anos de 1990, passando a atuar estrategicamente, focada na capacitação dos profissionaise nos resultados organi- zacionais, tendo os gestores de linha como gestores de pessoas (MARRAS, 2000; WOOD JR., 2000; GIL, 2001; DUTRA, 2002; FRANÇA, 2007; GIRARDI, 2008). Visando otimizar as diretrizes e os recursos para atingir os objetivos organizacionais, o estabelecimento de estratégias ganhou destaque. Fischer (2002) coloca que o foco estratégico é a face visível do desempenho da organização, a forma como é avaliada a sua competitividade externa. Para Ulrich (2000), o RH é importante, pois tem os desafios da globalização, lucratividade por meio do crescimento, tecnologia, capital intelectual e geração de mudanças. Nesse cenário, a liderança passou a se desenvolver como prática de gestão nas organizações voltadas às pessoas e ao futuro.

A amplitude de conceitos da Gestão de Pessoas na literatura identifica seu caráter descentralizado, de valorização das pessoas e de busca do desenvolvimento individual e organizacional, conforme mostra a definição de Gil (2001), de que a Gestão de Pessoas é uma função gerencial que busca a cooperação das pessoas, para o alcance dos objetivos organizacionais $e$ individuais.

O papel da Gestão de Pessoas é captar e manter os talentos humanos nas organizações, atuar de modo sistêmico, e em uma relação de parceria com os gestores de linha, buscando adequar estrutura, estratégias, processos e pessoas, para o alcance dos objetivos organizacionais. $\mathrm{O} \mathrm{RH}$ deve criar competências $e$ comportamentos, gerir a seleção, o treinamento, o desempenho, o reconhecimento e o desenvolvimento das pessoas (DESSLER, 2003), orientado para gerir o conhecimento e alavancar os resultados organizacionais.

A Gestão de Pessoas se torna efetiva por meio dos seus processos. Atualmente, os principais processos de Gestão de Pessoas citados na literatura, são conforme o Quadro1 a seguir:

\begin{tabular}{|c|c|c|c|c|c|}
\hline $\begin{array}{c}\text { Provisão de } \\
\text { Talentos }\end{array}$ & $\begin{array}{c}\text { Desenvolvimen- } \\
\text { to de Pessoas }\end{array}$ & $\begin{array}{l}\text { ManUTENÇão } \\
\text { DE TALENTOS }\end{array}$ & $\begin{array}{c}\text { RemuneraÇão } \\
\text { De Pessoas }\end{array}$ & $\begin{array}{c}\text { Monitoração } \\
\text { De Pessoas }\end{array}$ & $\begin{array}{l}\text { APlicação de } \\
\text { Pessoas }\end{array}$ \\
\hline $\begin{array}{l}\text {. Planejamento } \\
\text { de RH } \\
\text {. Atração e } \\
\text { Seleção de } \\
\text { Talentos } \\
\text {. Integração }\end{array}$ & $\begin{array}{l}\text { Treinamento e } \\
\text { Desenvolvimento } \\
\text {. Educação } \\
\text { Corporativa }\end{array}$ & $\begin{array}{l}\text { Qualidade de } \\
\text { Vida no Trabalho } \\
\text {. Higiene e } \\
\text { Segurança do } \\
\text { Trabalho } \\
\text {. Gestão de } \\
\text { Carreira }\end{array}$ & $\begin{array}{l}\text {. Plano de Cargos } \\
\text { e Salários } \\
\text {. Remuneração } \\
\text { Variável } \\
\text {. Benefícios Sociais }\end{array}$ & $\begin{array}{l}\text { Avaliação de } \\
\text { Desempenho } \\
\text {. Gestão de } \\
\text { Competências }\end{array}$ & $\begin{array}{l}\text { Liderança } \\
\text {. Coaching } \\
\text {. Trabalho } \\
\text { em Equipe } \\
\text {. Gestão do } \\
\text { Conhecimento }\end{array}$ \\
\hline
\end{tabular}

Quadro 1: Os processos de Gestão de Pessoas

Fonte: Elaborado pelos autores deste artigo 
Os processos de Gestão de Pessoas estão relacionados entre si, sob a perspectiva sistêmica, atuam em conjunto com a estratégia da organização, em um processo contínuo de gestão do capital humano, buscando agregar valor à empresa. Marras (2005) afirma que a concretização dos processos de Gestão de Pessoas é responsabilidade conjunta dos gestores de linha e do gestor de pessoas, como consultor interno. Cada gestor atua com a sua equipe de trabalho e o gestor de pessoas atua na estratégia organizacional, estabelecendo diretrizes e critérios para a gestão das pessoas.

Na sequência, caracteriza-se brevemente o processo de Aplicação de Pessoas.

\subsection{O Processo de Aplicação de Pessoas}

A Gestão de Pessoas nas organizações, por meio da Aplicação de Pessoas, busca ajustar, compatibilizar as pessoas aos processos de trabalho, aproveitar os talentos humanos da organização.

Os componentes desse processo são: a) Liderança; b) Coaching; c) Trabalho em Equipe; e d) Gestão do Conhecimento.

Coaching se refere à relação entre líderes e colaboradores, transmissão de experiência, incentivo e apoio ao alto desempenho, compartilhamento do conhecimento. (TERRA, 2005)

A Gestão do Conhecimento é a identificação, o desenvolvimento, a disseminação e a atualização do conhecimento relevante para a organização, por meio de processos internos ou externos à empresa (FLEURY; OLIVEIRA JR., 2008). Há dois tipos de conhecimento: a) Explícito - objetivo, formal, informações processadas; e b) Tácito - subjetivo, experiências, valores, a serem processados (NONAKA; TAKEUCHI, 1997). A Gestão de Pessoas deve orientar os seus esforços para a ação estratégica e de parceria com todos os gestores, para a criação e o desenvolvimento do conhecimento, especialmente o Tácito. A partir dos indivíduos, o conhecimento deve ser compartilhado, por meio da integração, troca de informações e de experiências.

Como tema desse estudo, a liderança conduz os gestores às demais práticas de gestão de pessoas. $\mathrm{O}$ coaching é um modelo de liderança, uma forma de gestão voltada às pessoas e ao seu desenvolvimento. $\mathrm{O}$ gestor precisa ter perfil de liderança e a organização apoiar o trabalho de coaching. A Gestão do Conhecimento ocorre por meio de políticas e práticas de apoio às pessoas e ao conhecimento, estabelecidas pela Gestão de Pessoas e compartilhadas com os gestores de linha, cujo desafio é liderar indivíduos e equipes para a busca do conhecimento e da inovação. A Gestão do Conhecimento busca encontrar as melhores formas de mobilizar e alavancar o conhecimento individual e integrá-lo ao conhecimento organizacional. (FIGUEIREDO, 2005) A liderança favorece também a comunicação, o clima organizacional, a gestão de conflitos e a gestão da mudança, subprocessos complementares do processo de Aplicação de Pessoas.

O tópico a seguir trata da liderança e das suas contribuições para a Gestão do conhecimento nas organizações.

\subsubsection{Liderança e Gestão do Conhecimento}

A liderança é uma ferramenta estratégica da Gestão de Pessoas, integrante do processo de Aplicação de pessoas, que agrega valor aos resultados e ao conhecimento das organizações. Para a compreensão do seu papel na Gestão do Conhecimento, é importante caracterizá-la, refletir sobre a sua evolução, conceituação, teorias, ações e perfil ideal do líder na atualidade.

Os estudos sobre a liderança no ambiente laboral foram realizados por profissionais das áreas de psicologia, sociologia e ciências políticas, destacando-se, em 1950, a Teoria das Necessidades de Abraham Maslow. Outros estudos relacionados envolvem categorias de Administração Científica de Taylor e ensaios de Hawtorne sobre moral dos empregados, estilos de supervisão, produtividade, nível de maturidade dos liderados, atuação da liderança na tarefa e em relações humanas, liderança situacional e estrutura de grupos. Tais estudos enfatizaram os aspectos pessoais e comportamentais no trabalho. Em 1960, McGregor propôs a Teoria X, da liderança autoritária, e a Teoria Y, da liderança participativa. Essas teorias influenciaram significativamente a teoria da administração. (LIMONGI-FRANÇA; ARELLANO, 2002)

Nos anos de 1980, a liderança passou a ser percebida como vantagem competitiva e se tornou objeto de atenção por parte dos estudiosos e das organizações. No contexto dinâmico dos anos de 1990, foi percebida a necessidade de um novo tipo de líder para o futuro, baseado no resgate de aspectos que fomen- 
tam a liderança eficiente, como clareza nos objetivos, motivação e envolvimento das pessoas no trabalho, desafios e outros. O foco passou a ser na distinção entre administração e liderança, como forma de suprir as limitações das ferramentas empresariais técnicas como planejamento e controle. (GALBRAITH, 1995)

No século XXI, as pessoas e os gestores das organizações refletem sobre o seu verdadeiro papel. De um lado, as pessoas buscam identificação e satisfação com o seu trabalho e também uma contribuição mais ampla e de outro, as organizações percebem a necessidade de alinhamento $e$ integração entre o meio ambiental, social e o mundo dos negócios e de revisão do comportamento gerencial. (CAVALCANTI, 2009) Assim, a liderança surge como ferramenta agregadora às organizações.

A conceituação da liderança é ampla na literatura. O Quadro 2 a seguir apresenta algumas definições de liderança:

\begin{tabular}{l|l|} 
Vergara & $\begin{array}{l}\text { Conjunto de estímulos, incentivos, } \\
\text { que motivem as pessoas a realizar } \\
\text { a missão, a visão e os objetivos } \\
\text { organizacionais (1999). }\end{array}$ \\
\hline $\begin{array}{l}\text { Limongi- } \\
\text { França; } \\
\text { Arellano }\end{array}$ & $\begin{array}{l}\text { Processo social em que se } \\
\text { estabelecem relações de influência } \\
\text { entre as pessoas (2002). }\end{array}$ \\
Cavalcanti & $\begin{array}{l}\text { Capacidade de influenciar } \\
\text { pessoas ou grupos (2009). }\end{array}$
\end{tabular}

Quadro 2: Definições de liderança

Fonte: Elaborado pelos autores deste artigo

Observa-se nos conceitos de liderança a ênfase em influenciar pessoas e equipes nas organizações, estimulando-as a realizar os seus propósitos. Bergamini (1994) avalia que a maioria das definições de liderança apresenta dois elementos comuns: a liderança como fenômeno grupal e a liderança como processo intencional de influência do líder sobre os seus seguidores.

A conceituação da liderança está relacionada às teorias da liderança. Segundo Cavalcanti (2009), há estudiosos que definem a liderança focando os traços, outros o estilo de influência. Ainda há aqueles que associam a liderança às contingências.

Os estudos sobre a liderança iniciaram com teorias simples, e com o tempo as investigações se tornaram mais complexas (CAVALCANTI, 2009). As teorias de liderança mais comuns na literatura são as seguintes:

a) Teoria Genética - é a mais antiga abordagem de liderança. Acreditava-se que a capacidade de liderança era transmitida geneticamente. $\mathrm{O}$ líder nasce feito, não é produzido. Desconsiderava a possibilidade de desenvolvimento de líderes (MONTANA; CHARNOV, 2003).

b) Teoria dos Traços - também crê no aspecto inato do líder. Segundo ela, os líderes possuem certas características, traços de personalidade, que favorecem o seu papel, como: estatura, inteligência, boa comunicação, flexibilidade, entusiasmo e outros.

c) Abordagem Comportamental - ou Teoria dos Estilos de Liderança. Alterou o foco de quem é o líder para o que ele faz, sua relação com os liderados. Propõe que os líderes podem ser preparados para exercerem o seu papel, adotando determinad o comportamento. O líder pode ser Autocrático (centralizador), Democrático (estimula a participação das pessoas), Orientado para a Tarefa (foca no trabalho, metas, prazos, custos, qualidade) ou Orientado para as Pessoas (foca no colaborador, relações humanas, apoia, desenvolve).

d) Abordagem Contingencial - ou Situacional. Acredita que a liderança depende do líder, dos seguidores, da situação do trabalho e da organização, ou seja, está atrelada a um conjunto de variáveis, que se complementam e facilitam o desempenho do líder. É uma visão complexa da liderança que enfatiza a adaptabilidade e a influência dos liderados sobre o líder (LIMONGI-FRANÇA; ARELLANO, 2002; MONTANA; CHARNOV, 2003; CAVALCANTI, 2009).

Atualmente, a competitividade requer das organizações atenção em diversos aspectos, entre eles, a renovação dos estilos de gestão, da forma de conduzir as pessoas no trabalho, enfatizando a importância da prática da liderança. Passou a haver diferenciação entre o gerente e o líder. O gerente está dando lugar ao líder, facilitador. Os gerentes fazem com que as pessoas realizem o que lhe foi delegado e os líderes integram a equipe nos negócios, estimulam resultados. Bennis (1996) avalia que enquanto o gerente administra, foca no trabalho com visão de curto prazo, o líder inova, foca nas pessoas, no futuro, em uma relação de confiança. O líder capacita, liberta, desafia. Assim, 
aumenta a demanda das empresas por gestores com perfil de líder. (CAVALCANTI, 2009)

Conforme o modo de uso do poder pelo líder, os resultados da liderança variam em termos de amplitude, o que remete a diferentes tipos de liderança, cada um com características particulares, sendo alguns deles:

a) Liderança Carismática - associada no carisma e nas habilidades de comportamento do líder percebidas pelos seguidores que possuem aceitação incondicional e envolvimento emocional com a missão da empresa (LIMONGI-FRANÇA; ARELLANO, 2002; CAVALCANTI, 2009).

b) Liderança Visionária - baseada na capacidade do líder de criar a visão do futuro, indo além da orientação para metas (CAVALCANTI, 2009).

c) Liderança Transacional - entende o processo de liderança como a ocorrência de transações com benefícios mútuos entre o líder $e$ a equipe em certo contexto; há o foco na relação de troca. O líder transacional observa o cumprimento dos padrões, ajusta o trabalho e reconhece realizações.

d) Liderança Transformacional - o líder e a equipe elevam-se mutuamente em relação à moralidade e à motivação, aumentando a conscientização, o comprometimento e a busca da autorrealização. O líder transformacional tem como foco o desenvolvimento das pessoas, a busca de desempenho além do cargo; possui carisma, inspiração, dá atenção a cada indivíduo, produz mudanças e promove o compartilhamento dos valores da empresa (LIMONGI-FRANÇA; ARELLANO, 2002; CAVALCANTI, 2009).

e) Liderança Participativa - une visão, empowerment e um conjunto de valores próprios $e$ declarados. Os líderes participativos abrem espaço para a experimentação, inovação, responsabilidade, autonomia sustentada, estimulam a comunicação, a aprendizagem, o conhecimento $e$ as oportunidades (BOOG; BOOG, 2006).

f) Liderança de Alta Performance - acentua a formação de equipes de trabalho, tendo o líder como catalisador de talentos na criação de novas competências e melhores resultados em um ambiente dinâmico e competitivo (LIMONGI-FRANÇA; ARELLANO, 2002).
Limongi-França e Arellano (2002) e Boog e Boog (2006) ressaltam o valor da liderança participativa, como forma de criar diferencial competitivo pela atuação efetiva dos indivíduos, cultura de comprometimento e união, habilidades adequadas e energia realizadora. Entretanto, nem todos estão preparados para serem participativos, cabendo à organização sistematizar políticas e programas de gestão para o amadurecimento das pessoas e a sua segurança para tomar decisões.

O tipo de liderança adotado pelos gestores depende dos seus valores, personalidade, habilidades e competências, contexto organizacional e motivação para resultados. Assim, um líder pode ser autocrático, colaborador ou visionário. (CAVALCANTI, 2009) Para que os líderes possam cumprir o seu papel, a organização deve estimular a liderança, ser receptiva à criatividade, à inovação, favorecendo a integração, a satisfação, a aprendizagem e o conhecimento.

As teorias e os estilos de liderança antecipam determinadas funções dos líderes e traços do seu perfil. Um líder deve ter um conjunto de habilidades, competências e conhecimentos que orientem as suas ações para o pleno aproveitamento do potencial humano, otimizando os resultados organizacionais.

O papel do líder envolve a gestão das metas e processos, das pessoas, das mudanças e o controle dos resultados, por meio das habilidades de coordenador, mentor, e inovador, focalizando o trabalho, desenvolvendo os colaboradores e estimulando o uso da criatividade (QUINN et al., 2003). O líder deve gerar uma tensão criativa positiva e gerenciá-la, manter o compromisso com a verdade e energizar a organização. (SENGE, 2006)

O líder deve avaliar o ambiente externo, estar atento a mudanças, ter habilidade de esclarecer problemas e contribuir para a formação de valores voltados à satisfação das pessoas na organização (VERGARA, 1999). O papel do líder é amplo, ele orienta sobre as estratégias da empresa e promove a adequação das atividades (ULRICH, 2000). Os líderes eficientes possuem habilidades aprendidas, atitudes desenvolvidas e valores e precisam alinhar e direcionar as pessoas para os propósitos organizacionais. (GALBRAITH, 1995)

O líder gerencia pessoas e equipes, é integrador, motivador, comprometido com o desenvolvimento dos indivíduos (HILL, 1993), com o compartilhamento de 
valores e aspirações, para a realização das metas organizacionais (CAVALCANTI, 2009). As organizações que aprendem investem na aprendizagem em equipe e na visão compartilhada, melhorando a qualidade do pensamento e a capacidade de reflexão. (SENGE, 2006)

Os líderes cumprem papel de educadores, devem se envolver e se responsabilizar pela aprendizagem das suas equipes, comprometidos com o sistema organizacional, criar uma cultura e valores de aprendizagem contínua, motivando as pessoas a usar toda a sua potencialidade e a elevar o seu desempenho (EBOLI, 2002). Milkovich e Boudreau (2006) refletem que a cúpula da empresa cria a cultura organizacional e os seus membros devem dar o exemplo em liderança, apoiando a implementação de mudanças. Senge (2006) ensina que as pessoas aprendem mais rápido quando têm a noção exata da responsabilidade pelas suas ações, sendo necessário que as organizações ampliem o poder por todos os níveis, dando liberdade às pessoas para que experimentem as suas ideias e sejam responsáveis pelos seus resultados. Nesse contexto, os líderes enfocam no propósito da empresa, na estrutura sistêmica, na inter-relação entre as partes, e ensinam os indivíduos a fazerem da mesma forma. Esses aspectos favorecem a busca de novos conhecimentos por parte das pessoas, para atualização e adequação aos valores e objetivos da empresa.

Galbraith (1995) avalia que os líderes fornecem suporte estratégico às organizações, em uma Gestão de Pessoas compartilhada entre o $\mathrm{RH}$ e os gestores de linha, criando envolvimento e contribuindo para a realização das estratégias e objetivos organizacionais.

É possível observar que a atuação dos líderes é ampla nas organizações. Suas funções são diversas, envolvendo desde o gerenciamento das metas, atividades e pessoas até a motivação individual e grupal, a orientação e a educação. Trata-se de uma gestão técnica e humana, em sintonia com as estratégias da organização, focalizando o desenvolvimento das pessoas e da organização e a competitividade.

Para cumprir as suas funções e desafios, o líder deve possuir determinado perfil. Com base na literatura, é possível traçar o perfil do líder eficaz, conforme consta no Quadro 3 a seguir:

\begin{tabular}{|c|c|c|c|}
\hline $\begin{array}{l}\text { Voltado para Valores } \\
\text { Visão estratégica e de futuro } \\
\text { Sensível ao ambiente } \\
\text { Foco nas pessoas e resultados } \\
\text { Carismático } \\
\text { Hábil em relacionamentos } \\
\text { Bom temperamento }\end{array}$ & $\begin{array}{l}\text { Confiável } \\
\text {. Hábil em } \\
\text { comunicação } \\
\text {. Ponderado } \\
\text {. Facilitador } \\
\text {. Motivador } \\
\text {. Educador } \\
\text {. Integrador }\end{array}$ & $\begin{array}{l}\text { Hábil no trabalho em equipe } \\
\text { Democrático } \\
\text { Flexível } \\
\text { Otimista } \\
\text { Autoconfiante } \\
\text { Proativo } \\
\text { Dinâmico }\end{array}$ & $\begin{array}{l}\text { Autoconhecimento } \\
\text { Autodesenvolvimento } \\
\text {. Ousado } \\
\text { Criativo } \\
\text {. Agente de mudanças } \\
\text {. Realizador } \\
\text {. Inovador }\end{array}$ \\
\hline
\end{tabular}

Quadro 3: Perfil do líder eficaz

Fonte: Elaborado pelos autores deste artigo

A reunião desse conjunto de características supra-citadas torna o líder preparado para gerir as pessoas, conduzi-las ao envolvimento e aos resultados organizacionais. Assim, os traços essenciais ao líder são integração dos valores seus e da organização, visão clara dos objetivos, estímulo e criação de condições para a criatividade e o conhecimento e busca do alto desempenho, para a competitividade organizacional (LIMONGI-FRANÇA; ARELLANO, 2002). Drucker (2002) corrobora o exposto, refletindo que a base da liderança eficaz é identificar a missão e torná-la clara, ter visão da responsabilidade pelos resultados organizacionais e promover inovação, por meio do trabalho e do conhecimento. Também são aspectos fundamentais aos líderes a habilidade interpessoal $e$ a de comunicação. A forma como o líder se relaciona e se comunica com a equipe favorece o desempenho; a liderança conduz o gestor a uma relação sincera $e$ à comunicação clara dos objetivos da organização. Cavalcanti (2009) ressalta que o autoconhecimento é essencial aos líderes, para a sua formação, desenvolvimento e manutenção do equilíbrio interior, para melhor lidar com as pessoas.

Os líderes devem agregar resultados à organização e, em conjunto com a Gestão de Pessoas descentralizada, promover os processos de $\mathrm{RH}$ de modo sistêmico e o conhecimento. Lacombe (2005) coloca que o RH orienta e apoia os gerentes, sensibilizando-os para a liderança, para que cada gestor de linha atue como líder, orientador e educador do seu grupo. Leite 
et al. (2005) confirma que a Consultoria Interna de RH orienta a organização para a visão sistêmica e para a liderança de pessoas e grupos.

A busca do conhecimento requer das organizações e da Gestão de Pessoas, cultura de liderança $e$ apoio contínuo ao desenvolvimento gerencial $e$ de líderes potenciais. Por meio de processos de $\mathrm{RH}$ alinhados às estratégias de negócio, descentralizados e integrados entre si, a Gestão de Pessoas auxilia no desenvolvimento da liderança, dos talentos humanose na sua capacidade de envolvimento com os resultados organizacionais. Por isso, os processos de Seleção, Treinamento e Desenvolvimento e Avaliação de Desempenho devem ser bem trabalhados, além da Remuneração e da Qualidade de Vida no Trabalho, resultando em talentos humanos valiosos para a organização, capacitados, cientes das suas capacidades e pontos a melhorar (feedback), motivados e comprometidos.

A organização e a Gestão de Pessoas devem fomentar a liderança, desenvolver líderes e liderados, identificar aqueles que têm potencial para a liderança e cultivá-los como recursos de valor (GALBRAITH, 1995). Um investimento significativo nesse sentido é o programa de trainee, cujo objetivo é captar e desenvolver jovens talentos com alto potencial, desenvolvendo competências para a construção de uma carreira sólida e a ocupação futura de cargos de liderança (PACHECO, 2005). Profissionais talentosos assumem a sua inclinação para a liderança, as incertezas e os riscos, e têm disposição para progredir (DRUCKER, 2005).

Assim, liderança é fundamental às organizações, contribuindo para a integração efetiva entre as pessoas e as estratégias e para a Gestão do Conhecimento, estimulando a participação e o aprendizado, gerando, desenvolvendo e disseminando novos conhecimentos, orientados para a inovação $e$ a competitividade organizacional.

A seguir são apresentados os procedimentos metodológicos do estudo.

\section{Procedimentos Metodológicos}

Com base no objetivo desse estudo, adotou-se a linha de pesquisa Qualitativa, Descritiva e Aplicada. Para a coleta de dados, foram utilizadas a Pesquisa Documental e a Entrevista semiestruturada.
A população da pesquisa foram as indústrias catarinenses de grande porte, em razão da estrutura do $\mathrm{RH}$, da possibilidade de investimentos na área $e$ da gestão descentralizada de pessoas. Foi selecionada de uma lista da FIESC, uma Amostra Intencional de dez indústrias, as que possuíam maior número de colaboradores, buscando uma análise qualitativa em profundidade, sem a intenção de generalização dos dados. Os gestores de pessoas, de processos e, caso houvesse, o consultor interno foram os Sujeitos da pesquisa. Das dez indústrias da amostra, sete foram pesquisadas, pela disponibilidade. As dez indústrias catarinenses selecionadas para a pesquisa foram: 1) Aurora; 2) Weg; 3) Sadia; 4) Perdigão; 5) Busscar; 6) Tupy; 7) Malwee; 8) Whirlpool - Multibrás; 9) Teka; e 10) Whirlpool - Embraco. O Quadro 4 a seguir apresenta as sete maiores indústrias do Estado de Santa Catarina pesquisadas:

\begin{tabular}{|l|c|}
\hline \multicolumn{1}{|c|}{ EMPRESA } & $\begin{array}{c}\text { NÚMERODE } \\
\text { COLABORADORES }\end{array}$ \\
\hline $\begin{array}{l}\text { Aurora - Cooperativa Central } \\
\text { Oeste Catarinense }\end{array}$ & 27.508 \\
\hline Weg & 14.420 \\
\hline Sadia & 13.109 \\
\hline Tupy S/A & 7.500 \\
\hline Whirlpool S/A - Multibrás & 6.000 \\
\hline Teka Tecelagem Kuehnrich S/A & 5.950 \\
\hline Whirlpool S/A - Embraco & 5.400 \\
\hline
\end{tabular}

Quadro 4: Empresas pesquisadas

Fonte: Elaborado pelos autores deste artigo

A análise de dados seguiu o método de Análise de Conteúdo, focado na Análise por Categoria. Não há identificação das empresas na análise dos dados por motivo de sigilo.

As práticas de liderança nas indústrias catarinenses de grande porte são descritas na sequência.

\section{A Liderança nas Maiores Indústrias do Estado de Santa Catarina}

O estudo buscou identificar as práticas de liderança e a sua contribuição para a Gestão do Conhecimento. 
De acordo com os dados coletados, na empresa 1 , há a estratégia denominada "nossas pessoas". O $\mathrm{RH}$ atua com base em três premissas: 1) trust and engagement, ou seja, confiança e comprometimento; 2) gestão de talentos; e 3) gestão de performance. A empresa tem pensamento de liderança diferenciado. "Essa é a nossa ótica, um pensamento de liderança voltado pra gestão de pessoas, desenvolver os nossos líderes, o jeito de liderar". As competências necessárias aos líderes da organização são definidas, bem como a avaliação dos líderes, buscando aperfeiçoamento por meio de treinamentos e desenvolvimentos, bem como a integração entre líderes. A empresa possui o programa way of leading, para a formação dos líderes. Há o desenvolvimento de carreira, atrelado à avaliação de desempenho, incluindo os trainees.

Na empresa 2 há práticas relacionadas à liderança, porém, ela não foi mencionada diretamente. Tais práticas são focadas no conhecimento, nos "[...] grupos do conhecimento, na comunicação e na relação interpessoal". Também há preocupação com a inovação, sendo a área de engenharia de produtos a responsável pela inovação na empresa.

A empresa 3 tem consultores internos e programas voltados à liderança, para o desenvolvimento de competências e internalização dos preceitos essenciais da empresa, como MBA in company, visando o desenvolvimento comportamental.

Na empresa 4, a liderança se manifesta por meio da ação conjunta dos gestores e colaboradores no planejamento do desenvolvimento individual (coaching). Conforme o entrevistado, "[...] valoriza-se muito o papel do gestor no desenvolvimento das suas equipes". Isso demonstra gestão descentralizada, valorização das pessoas e oportunidades de crescimento. A empresa "[...] tem um desenho de carreira em Y que permite que o profissional tenha possibilidades de crescimento tanto na carreira técnica quanto na gerencial".

Já na empresa 5, há o "PDL (Plano de Desenvolvimento de Líderes)" e incentivo para o coaching. Foi destacada parceria entre o $\mathrm{RH}$, os gestores e os funcionários. A empresa cuida da Gestão do Conhecimento, sendo a maioria das informações centralizadas no $\mathrm{RH}$ corporativo, o qual registra e dissemina para as demais unidades. A entrevistada citou nesse sentido: "[...] a gente procura ter o máximo de facilidade para as pessoas trazerem as informações, com qualquer área. Assim, as pessoas têm essa liberdade. Depois isso tudo fica, de certa forma, registrado, até para a gente não perder".

A empresa 6 possui consultoria interna, atuante nos níveis tático e operacional. Foi ressaltada a intensificação do trabalho em equipe, associado à liderança, o que muda a relação de liderança existente, "tanto do líder quanto do liderado; então isso foi bastante intensificado", colocou o entrevistado. A empresa denomina esse processo de trabalho em times, e percebe-se que isso é valorizado pelos funcionários, com participação elevada e efetiva, resultando em melhorias significativas no processo produtivo, envolvendo baixo custo e gerando comprometimento. Cabe destacar que o comprometimento é essencial à Gestão do Conhecimento, pois permite e estimula o compartilhamento de conhecimento. Há na empresa programas de melhoria contínua e plano de carreira, porém, a empresa reconheceu que precisa repensar o desenvolvimento das pessoas, antes um processo mais efetivo, o que ampliaria as competências de liderança e o conhecimento na empresa.

Por fim, a empresa 7 também apresenta consultores internos, assumindo a tomada de decisão nos níveis tático e estratégico. A empresa treina todos os seus gestores em técnicas de coaching, baseada na carreira Y. Quanto aos colaboradores, somente em alguns casos é pensado na preparação do profissional para funções futuras, limitando assim o desenvolvimento de líderes e o aproveitamento pleno dos talentos humanos da organização.

Uma síntese da análise das práticas de liderança nas empresas estudadas consta no Quadro 5 a seguir:

\begin{tabular}{|l|l|}
\hline \multicolumn{1}{|c|}{$\begin{array}{c}\text { EmPRESAS } \\
\text { PESQUISADAS }\end{array}$} & \multicolumn{1}{c|}{ PrÁticAS DE LiDERANÇA } \\
\hline Empresa 1 & $\begin{array}{l}\text { Programa Way ofleading, destinado a } \\
\text { formar os líderes. }\end{array}$ \\
\hline Empresa 2 & $\begin{array}{l}\text { Em processo de mudança. Identificadas } \\
\text { ações relacionadas à liderança. Grupos } \\
\text { do conhecimento, foco na comunicação, } \\
\text { relação interpessoal e inovação. }\end{array}$ \\
\hline Empresa 3 & $\begin{array}{l}\text { Programa de formação de liderança. MBA } \\
\text { in company, focado no desenvolvimento } \\
\text { comportamental. }\end{array}$ \\
\hline Empresa 4 & $\begin{array}{l}\text { Plano de carreira Y para as áreas técnica } \\
\text { e gerencial. Coaching. }\end{array}$ \\
\hline
\end{tabular}

Quadro 5: Comparativo quanto às práticas de liderança Fonte: Adaptado de Girardi (2009) 


\begin{tabular}{|l|l|}
\hline \multicolumn{1}{|c|}{$\begin{array}{c}\text { EMPRESAS } \\
\text { PESQUISADAS }\end{array}$} & \multicolumn{1}{c}{ PrÁticas DE LidERANÇA } \\
\hline Empresa 5 & $\begin{array}{l}\text { PDL (Plano de Desenvolvimento de } \\
\text { Líderes). Coaching. }\end{array}$ \\
\hline Empresa 6 & $\begin{array}{l}\text { Ações relacionadas à liderança. Trabalho } \\
\text { em equipe, plano de carreira. Empresa } \\
\text { assumiu a necessidade de retomar o } \\
\text { desenvolvimento das pessoas. }\end{array}$ \\
\hline Empresa 7 & $\begin{array}{l}\text { Treinamento dos gestores em técnicas } \\
\text { de coaching. Carreira Y. Preparo de } \\
\text { colaboradores para funções futuras. }\end{array}$ \\
\hline
\end{tabular}

Quadro 5: Comparativo quanto às práticas de liderança Fonte: Adaptado de Girardi (2009)

Nesse ponto, cabe destacar o clima organizacional e a comunicação interna, meios de auxiliar a Gestão do Conhecimento nas organizações e desafios dos líderes. O clima e a comunicação são efeitos da prática da liderança, portanto, quanto maior for a amplitude da liderança na organização, mais favoráveis esses serão à Gestão do Conhecimento. O entrevistado da empresa 1 citou "o clima de camaradagem", a informalidade na organização. Em relação à comunicação, a empresa 2 relatou a ocorrência de processos voltados à comunicação, relações interpessoais e ao conhecimento e a empresa 5 destacou a liberdade das pessoas em trazerem informações e o seu cuidado com o registro $e$ a disseminação das mesmas, com foco na Gestão do Conhecimento. A chave do processo de Aplicação de Pessoas em relação à Gestão do Conhecimento está na comunicação interna e na construção de um ambiente organizacional saudável, assim como nos casos analisados.

\section{Conclusões}

As pessoas são os elementos centrais da competitividade organizacional, agregam esforços, experiências, inteligência e conhecimento. A liderança é um instrumento importante para a orientação dos indivíduos para o conhecimento e o desenvolvimento das organizações.

Uma organização competitiva possui uma Gestão de Pessoas estratégica e descentralizada, focada nas pessoas e no seu valor para a realização dos seus objetivos, com atuação efetiva dos gestores de linha, em um esforço conjunto para a Gestão do Conhecimento.
Como ferramenta do processo de Aplicação de Pessoas, a liderança é um meio de influenciar os indivíduos $e$ as equipes, buscar comprometimento, integração e melhor desempenho, uma forma de gestão que conduz ao desenvolvimento das pessoas e da organização.

Por meio da liderança, os gestores de linha promovem os processos de Gestão de Pessoas, com o apoio do RH estratégico, resultando em conhecimento, inovação e competitividade. O perfil do líder é determinante para o êxito do processo, devendo este reunir um conjunto de valores, habilidades interpessoais, de comunicação, motivação, trabalho em equipe, mantendo clima organizacional favorável, atuando como facilitador agente de mudanças, estimulando as pessoas para o trabalho, capacitação contínua, criação, desenvolvimento e aplicação do conhecimento.

O líder deve dar significado para a vida das pessoas, desenvolver, recompensar o comprometimento com os resultados (SOUZA, 2010). O gerente líder tem visão humanista, percebe a organização como sistema social, em que as pessoas têm papel importante. Valoriza os interesses pessoais e os da organização, promove o trabalho em equipe, em uma relação de confiança e respeito mútuo, para conduzir as pessoas ao alto desempenho, torná-las motivadas e comprometidas com os objetivos organizacionais. (CAVALCANTI, 2009)

É possivel avaliar que na maioria das empresas estudadas, a liderança é tratada como ferramenta estratégica. Há programas de desenvolvimento de líderes e descentralização da Gestão de Pessoas, aspectos que possibilitam o envolvimento estratégico dos gestores de linha, a criatividade, a Gestão do Conhecimento, a inovação e a competitividade organizacional. As práticas observadas identificaram prioridade na criação de mecanismos que permitam a socialização, combinação e criação do conhecimento entre os funcionários.

Entretanto, há ainda algumas ações não bem desenvolvidas, como nas empresas 2, 6 e 7. As duas primeiras possuem direcionamento para a liderança, focando na comunicação, relação interpessoal, conhecimento, inovação (Empresa 2), trabalho em equipe (Empresa 6). As empresas 6 e 7 requerem maior foco no desenvolvimento das pessoas, o que ampliaria o seu potencial de liderança.

Assim, é desafio às organizações contemporâneas a mobilização estratégica para a liderança. Uma cultura 
apoiadora e o RH estratégico favorecem a ação efetiva dos gestores, a motivação, a Gestão do Conhecimento, os resultados organizacionais e a competitividade, por meio do desenvolvimento individual e da organização.

\section{REFERÊNCIAS}

BENNIS, W. A formação do líder. São Paulo: Atlas, 1996.

BERGAMINI, C. W. Liderança: administração do sentido. São Paulo: Atlas, 1994.

BOOG, G. G.; BOOG, M. T. (Org.) Manual de treinamento e desenvolvimento: processos e operações. São Paulo: Pearson Prentice Hall, 2006.

CÂMARA, P. B. da; GUERRA, P. B.; RODRIGUES, J. V. Humanator: recursos humanos e sucesso empresarial. São Paulo: Dom Quixote, 1997.

CAVALCANTI, V. L. Liderança e motivação. 3. ed. Rio de Janeiro: FGV, 2009.

DESSLER, G. Administração de recursos humanos.

2. ed. São Paulo: Prentice Hall, 2003.

DUTRA. J. S. Gestão de pessoas: modelo, processos, tendências e perspectivas. São Paulo: Atlas, 2002.

DRUCKER, P. F. O melhor de Peter Drucker: obra completa. São Paulo: Nobel, 2002.

O futuro do gerenciamento. In: Coletânea

executive excellence. Rio de Janeiro: Qualitymark, 2005.

FEDERAÇÃO das Indústrias do Estado de Santa Catarina (FIESC). Guia web SC: o guia da indústria de Santa Catarina. Disponível em: < http://www.fiescnet.com.br/ guiawebsc/>. Acesso em: 10 maio 2008.

FISCHER, R. M. Mudança e transformação organizacional. In: FLEURY, M. T. L. (Coord.). As pessoas na organização. São Paulo: Editora Gente, 2002. p. 147-164.

FRANÇA, A. C. L. Práticas de recursos humanos: conceitos, ferramentas e procedimentos. São Paulo: Atlas, 2007.
EBOLI, M. O desenvolvimento das pessoas e a educação corporativa. In: FLEURY, M. T. L. (Coord.). As pessoas na organização. São Paulo: Editora Gente, 2002. p. $185-216$.

\section{FIGUEIREDO, S. P. Gestão do conhecimento:}

estratégias competitivas para a criação e mobilização do conhecimento na empresa. Rio de Janeiro: Qualitymark, 2005.

FLEURY, M. T. L.; OLIVEIRA JR., M. de M. (Org.).

Gestão do conhecimento: integrando aprendizagem, conhecimento e competências. São Paulo: Atlas, 2008.

\section{GALBRAITH, J. R. Organizando para competir no} futuro. São Paulo: Makron Books, 1995.

GEUS, A. de. A empresa viva. Rio de Janeiro: Campus; São Paulo: Publifolha, 1999.

GIL, A. C. Gestão de pessoas: enfoque nos papéis profissionais. São Paulo: Atlas, 2001.

\section{GIRARDI, D. Da seção de pessoal à gestão} estratégica de pessoas: consultoria interna de recursos humanos. Florianópolis: Pandion, 2008.

\section{O compartilhamento dos processos de} recursos humanos: uma Contribuição para a Gestão do Conhecimento Organizacional. Florianópolis, 2009. 169 f. Tese (Doutorado) - Programa de Pós-Graduação em Engenharia e Gestão do Conhecimento. Universidade Federal de Santa Catarina.

HILL, L. A. Novos gerentes: assumindo uma nova identidade. São Paulo: Makron Books, 1993.

JOHRI, H. P.; COOPER, J. C.; PROKOPENKO, J. Managing internal consulting organizations: a new paradigm. Advanced Management Journal, v. 63, n. 4, p. 4-10, Outono 1998. Disponível em: <http:// www.freepatentsonline.com/article/SAM-AdvancedManagement-Journal/53450458.html > . Acesso em: 27 ago. 2010.

LACOMBE, F. J. M. Recursos humanos: princípios e tendências. São Paulo: Saraiva, 2005.

LEITE, L. A. M. da C. et al. Consultoria em gestão de pessoas. Rio de Janeiro: Editora FGV, 2005. 
LIMONGI-FRANÇA, A. C.; ARELLANO, E. B. Liderança, poder e comportamento organizacional. In: FLEURY, M.

T. L. (Coord.). As pessoas na organização. São Paulo: Editora Gente, 2002. p. 259-269.

\section{MANCIA, L. T. S. Os desafios do modelo de}

consultoria interna: uma experiência gaúcha.

Porto Alegre. 1997. 184 f. Dissertação (Mestrado em

Administração). Universidade Federal do Rio Grande do

Sul. Disponível em: < http:/www.bibliotecadigital.ufrgs.br/ da.php?nrb $=000098516 \& l o c=2006 \& \mathrm{l}=\mathrm{a} 6594432 \mathrm{a} 6 \mathrm{dd} 3$ $46 c>$. Acesso em: 12 jun. 2010.

MARRAS, J. P. Administração de recursos humanos: do operacional ao estratégico. 3. ed. São Paulo: Futura, 2000 .

\section{Gestão de pessoas em empresas}

inovadoras. São Paulo: Futura, 2005.

MILKOVICH, G. T.; BOUDREAU, J. W. Administração de recursos humanos. São Paulo: Atlas, 2006.

MONTANA, P. J. CHARNOV, B. H. Administração. São Paulo: Saraiva, 2003.

NONAKA, I.; TAKEUCHI, H. Criação de

conhecimento na empresa: como as empresas japonesas geram a dinâmica da inovação. 16. ed. Rio de Janeiro: Elsevier, 1997.

PACHECO, L. Capacitação e desenvolvimento de pessoas. Rio de Janeiro: FGV, 2005.

QUINN, R. et al. Competências gerenciais: princípios e aplicações. Rio de Janeiro: Elsevier, 2003.

SENGE, P. M. A quinta disciplina: arte e prática da organização que aprende. 21. ed. São Paulo: Editora Best Seller, 2006.

SOUZA, C. A construção do líder Y. Melhores Você SA, São Paulo, n. 145, 13 de agosto de 2010, p. 74-75.

TERRA, J. C. C. Gestão do conhecimento: o grande desafio empresarial. Rio de Janeiro, Elsevier, 2005.

ULRICH, D. Recursos humanos estratégicos: novas perspectivas para os profissionais de RH. São Paulo: Futura, 2000.
VERGARA, S. C. Gestão de pessoas. São Paulo: Atlas, 1999.

WOOD JR. T. Mudança organizacional e transformação da função recursos humanos. In: WOOD JR. T.(Coord.). Mudança organizacional: aprofundando temas atuais em administração de empresas. 2. ed. São Paulo: Atlas, 2000. p. 239-260. 